\title{
MEMBRANE DISTILLATION FOR SEAWATER DESALINATION APPLICATIONS IN VIETNAM: POTENTIAL AND CHALLENGES
}

\author{
Duong Cong Hung ${ }^{1, *}$, Phan Duc Nhan ${ }^{2}$, Nguyen Van Tinh², Pham Manh Thao ${ }^{2}$, \\ Nguyen Cong Nguyen ${ }^{3}$
}

\author{
${ }^{I}$ Strategic Water Infrastructure Laboratory, School of Civil Mining and Environmental \\ Engineering, University of Wollongong, Wollongong, NSW 2522, Australia \\ ${ }^{2}$ Le Quy Don Technical University, 236 Hoang Quoc Viet, Cau Giay, Ha Noi, Viet Nam \\ ${ }^{3}$ Faculty of Environment and Natural Resources, Dalat University, Viet Nam
}

*Email: hungduongcong@gmail.com

Received: 20 September 2017; Accepted for publication: 24 October 2017

\begin{abstract}
Desalination of seawater and brackish water can be a practical approach to augmenting fresh water resources and hence mitigating the fresh water scarcity in Vietnam. Current seawater desalination plants utilize either thermal distillation or pressure-driven membrane separation technologies. Membrane distillation (MD) is a hybrid process, in which thermal distillation is combined with membrane separation. The MD process inherits notable attributes from both thermal distillation and membrane separation, including super quality distillate, low susceptibility to the feed osmotic pressure, negligible feed water pre-treatment, low investment and operational costs, and process modularization. Thus, MD has emerged as a promising technology platform for small-scale seawater desalination applications. This paper provides a comprehensive review of the seawater MD desalination process. The fundamentals of the MD process including configurations, membrane modules, membrane properties, and heat and mass transfer mechanisms together with approaches to enhancing heat and mass transfer are first systematically reviewed and analyzed. Then, the potential and challenges (e.g. most notably membrane wetting and fouling and energy consumption) of the seawater MD desalination process are thoroughly discussed. The analyses and discussions provided in this review paper help shed light on the viability of MD for fresh water provision in remote coastal and rural areas in Vietnam.
\end{abstract}

Keywords: membrane distillation, seawater desalination, fresh water scarcity, desalination processes.

\section{INTRODUCTION}

Fresh water scarcity has become a burning issue in many parts of Vietnam, particularly in remote coastal and rural areas. The growing population together with limited infrastructure and financial capacity have created intense stress on fresh water provision in the country. It is reported that less than a half of Vietnam population have access to fresh water for drinking and sanitation [1], while the majority of the country population (i.e. mostly in rural areas) have to 
rely on groundwater and harvested rainwater to meet fresh water demand [2]. There have been evidences that in many areas in Vietnam, groundwater has been contaminated by various toxic chemicals from industrial activities and agricultural runoff pollution [2]. Drinking water sourced from the contaminated groundwater can result in chronic health issues such as cancer, neurological and skin problems [3]. Harvesting rainwater is a simple, effective, and environmentally friendly method, and hence it is used complementarily to groundwater extraction to meet fresh water demand in both rural and urban areas in Vietnam. However, like in many other countries, rainwater patterns in Vietnam have been strongly affected by climate change, leading to long and severe drought seasons. Thus, rainwater harvesting is not a secured method to sufficiently provide fresh water during the drought seasons in Vietnam.

Seawater desalination can be a practical solution to augmenting fresh water resource and mitigating fresh water scarcity in Vietnam. In many countries around the world, large-scale desalination plants using either traditional thermal distillation or pressure-driven reverse osmosis (RO) processes have been effectively practiced to extract fresh water from seawater [4]. The traditional thermal distillation processes (e.g. multi-stage flash (MSF) and multi-effect distillation (MED)) involve boiling seawater to induce water vaporization and subsequently condensing water vapor to obtain fresh distillate. Huge amounts of heating and cooling are required to achieve the phase conversion of water; thus, MSF and MED are notorious for being energy-intensive $[5,6]$. On the other hand, the seawater RO process utilizes a high-pressure pump to push water through a dense semipermeable membrane. The dense RO membrane is highly permeable to water while retaining almost all suspended solids and dissolved substances in the feed stream. As a membrane process, RO is more energy-efficient than the traditional thermal distillation; therefore, most of recent seawater desalination installations in the world are based on the RO technology. However, because of high applied pressure, the RO process equipment and components are required to be manufactured from expensive, non-corrosive stainless steel. In addition, during the seawater RO process, rejected suspended solids and salts can accumulate on the membrane surface and foul the membrane, leading to reduction in the process water flux or increase in the operating pressure. To prevent and control membrane fouling, the RO process requires extensive seawater feed pre-treatment (e.g. chlorination, coagulation, acid and anti-scalant addition, multi-media and micron cartridge filtration, and dechlorination) together with frequent membrane cleaning [5, 6]. Given the above reasons, both the traditional thermal distillation and RO processes are only economically feasible for largescale seawater desalination applications, which are not suitable for fresh water provision in remote rural and coastal areas in Vietnam. The ideal seawater desalination process for Vietnam needs to be technically and economically viable to provide fresh water to small-scale, decentralized, and remote communities.

Membrane distillation (MD), which is a hybrid of traditional thermal distillation and membrane separation, can be an ideal technology platform for small-scale seawater desalination applications in Vietnam remote coastal and rural areas. In MD, a hydrophobic microporous membrane is used as a physical barrier to selectively allow the permeation of water vapor while rejecting liquid water and hence all non-volatile impurities and dissolved salts [7, 8]. A water vapor pressure difference induced by a temperature gradient across the membrane is the driving force for the transfer of water vapor through the membrane in the MD process, thus obviating the needs for high-pressure pumps as required in RO. This allows the MD systems to be manufactured from inexpensive plastic materials to reduce the process investment costs. In addition, compared to the seawater RO process, seawater MD desalination is significantly less prone to membrane fouling, hence requiring negligible seawater feed pre-treatment. Compared to the thermal distillation, the MD process can be efficiently operated at lower feed temperature 
(i.e. in the range from 40 to $80{ }^{\circ} \mathrm{C}$ ) [9 - 11]. Low-grade heat sources such as waste heat or solar thermal energy can be utilized to meet the primary energy demand of the seawater MD process. As a result, operational costs of the seawater MD desalination process can be much lower than those of traditional thermal distillation and RO [12].

This paper aims at providing a comprehensive review of the seawater MD desalination process to elucidate its potential for fresh water provision in Vietnam. The review begins with providing the fundamental knowledge of MD including process configurations, membrane modules, membrane properties, and heat and mass transfer mechanisms. The influences of operating conditions on the MD process performance and approaches to improving the process performance are then critically discussed and analyzed. The potential and technical challenges of the seawater MD desalination process for fresh water provision in Vietnam are also thoroughly delineated.

\section{MD CONFIGURATIONS, MODULES, AND MEMBRANES}

\subsection{MD configurations}

In the MD process, the movement of vapor through membrane pores is driven by a transmembrane vapor pressure gradient. To induce and maintain the vapor pressure gradient, a warm aqueous solution is kept in direct contact with the membrane on the feed side, while an air layer or various fluids are maintained on the permeate side (Figure 1). Depending on the fluid applied on the permeate side, membrane distillation is classified into four major configurations, including direct contact membrane distillation (DCMD), air gap membrane distillation (AGMD), vacuum membrane distillation (VMD), and sweeping gas membrane distillation (SGMD).

In DCMD, cold water is circulated tangentially to the membrane surface in the permeate side to induce the driving force (Figure 1). The vapor condensation into distillate occurs inside the permeate (i.e. distillate) channel of the DCMD membrane module. Thus, DCMD is the simplest and most suitable configuration for separation applications in which water is the main component of the feed solution (e.g. seawater and saline wastewater desalination) [7, 8 . However, due to its simple arrangement (i.e. the hot feed and cold distillate streams are separated by only a thin membrane), in DCMD there exists a noticeable heat loss due to conduction through the membrane from the feed to the distillate stream. As a result, DCMD exhibits lower thermal efficiency compared to other MD configurations [7, 8].

The heat loss due to conduction through the membrane is alleviated in AGMD. In this configuration, a condenser is inserted to generate an air gap on the permeate side of the membrane (Figure 1). The air gap functions as a heat insulation layer to reduce the conductive heat loss. In addition, as the condenser separates the distillate and the coolant streams, seawater can be first fed to the coolant channel and function as the coolant prior to being additionally heated and entering the feed channel (Figure 1). This arrangement enables the recovery of the latent heat of water vapor condensation inside the AGMD membrane module to pre-heat the feed stream, and obviates the need for cooling that is required in other MD configurations [13, 14]. Therefore, AGMD demonstrates the highest thermal efficiency, and is the most widely used configuration in pilot MD systems for seawater desalination applications. However, the air gap also increases the resistance to water vapor transfer, hence leading to a lower water flux of AGMD as compared to DCMD.

In VMD, vacuum is applied in the permeate side of the membrane to establish the driving force. The condensation of water vapor into distillate occurs in an external condenser (Figure 1). 
Given this arrangement, VMD has a lower heat loss due to conduction through the membrane than DCMD. It also has lower resistance to water vapor transfer than AGMD and DCMD because of the removal of stagnant air from the module. Consequently, high water flux and high thermal efficiency are viable for the VMD process [15]. However, the VMD process is highly prone to membrane pore wetting because of its high interfaces pressure difference [7, 15]. The VMD process also requires more equipment (e.g. vacuum pumps and condensers), hence rendering it more complicated and costly than DCMD and AGMD. As a result, the VMD process is best suited for applications to remove or to enrich volatile substances.

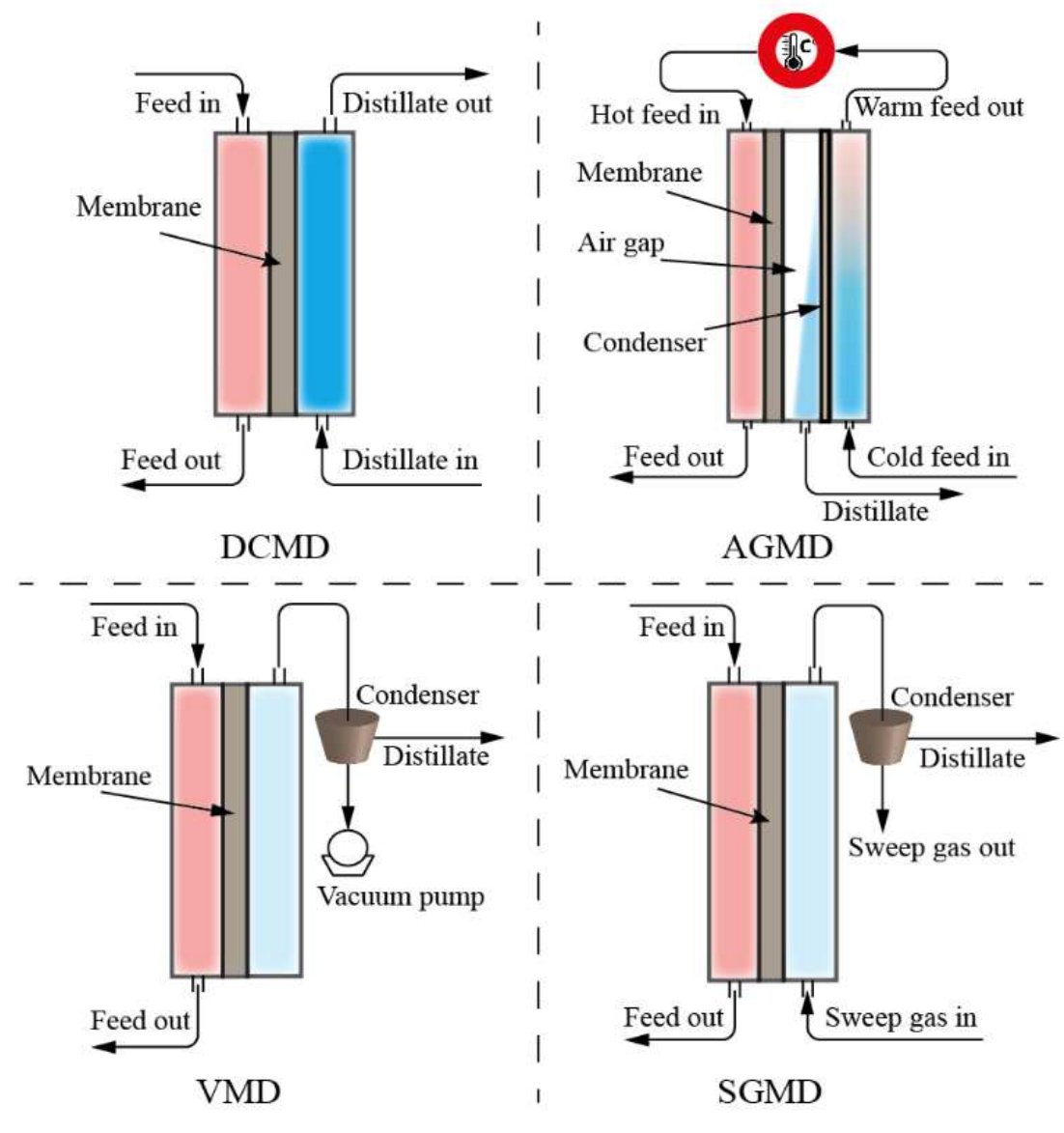

Figure 1. Schematic diagram of the four main MD configurations.

In SGMD, an inert cold gas stream is circulated through the permeate side of the membrane transferring water vapor to an external condenser in which the condensation occurs. The stationary air layer in AGMD is replaced by flowing gas in SGMD. The process water flux and thermal efficiency are, therefore, enhanced in the latter configuration [8]. However, system complexity, additional costs, and inert gas consumption are the main drawbacks of SGMD. Given these features, the SGMD process has limited applications, and has received little attention in the MD literature [8].

Different MD configurations have their own advantages and drawbacks. Thus, there have been intensive studies on MD configuration modification to enhance its performance. As a notable example, Cath et al. [16] investigated the performance of an enhanced DCMD process, in which vacuum was applied in the feed and distillate channels. The applied vacuum helped 
partially eliminate the air film in the membrane pores and consequently reduce the membrane resistance to the mass transfer. Thus, the mass transfer coefficient of water vapor and hence water flux of the enhanced process was increased as compared to the traditional DCMD process [16]. The AGMD configuration has been also modified for water flux improvement. The stagnant air layer is replaced by a distillate gap in a variation termed permeate gap membrane distillation (PGMD) $[17,18]$. The replacement of the air layer by the distillate gap helps reduce the mass transfer resistance and hence enhance water flux of the PGMD process. Moreover, because the coolant and the distillate streams are separated by a non-permeable thermal conductive foil, similarly to AGMD the internal recovery of the latent heat of condensation is also achievable in PGMD [17, 18]. The internal latent heat recovery is also applied in a modified configuration called vacuum multi-effect membrane distillation (VMEMD) [19]. A schematic diagram of the VMEMD configuration is illustrated in Figure 2. Multi-effect arrangement facilitates the recovery of the latent heat of condensation inside the VMEMD membrane module, whereas the applied vacuum helps increase the water vapor transfer through the membrane [20 22]. The condensation of water vapor to distillate occurs both inside the VMEMD membrane module and in an external condenser (Figure 2).

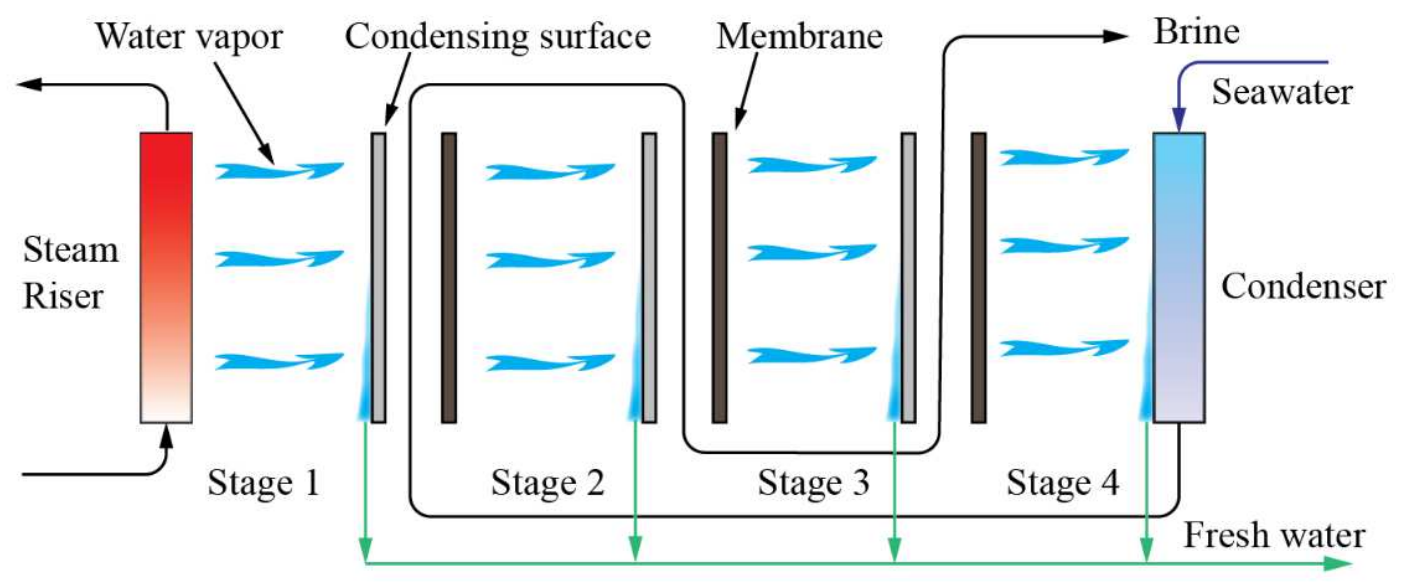

Figure 2. The schematic diagram of VMEMD.

\subsection{MD membranes and modules}

A key requirement for the MD process to sustain its separation efficiency is that the membrane pores must be dry, and only vapor can permeate through the membrane pores while liquid water and non-volatile impurities and dissolved salts are retained on the feed side of the membrane. The dry condition of the membrane pores in the MD process is achieved using hydrophobic and microporous membranes. Intrinsic hydrophobic polymers with low surface energy, including polytetrafluoroethylene (PTFE), polypropylene (PP) and polyvinylidene difluoride (PVDF), are the most widely used for MD membrane fabrication. Amongst these, PTFE membranes exhibit the best features desired for the MD process such as satisfactory water flux, high wetting resistance due to the excellent membrane hydrophobicity, and high chemical and thermal stability; therefore, they are the most used in commercial pilot MD systems [19, 23]. However, the fabrication of PTFE membranes entails considerable difficulties as compared with other polymers. Indeed, PTFE membranes can only be prepared using sintering or meltextrusion methods that involve additional toxic chemicals (e.g. solvents and volatile lubricating agents) and complicated processes (e.g. extrusion, thermal expansion, and stabilization by thermal annealing) $[19,23]$. The complexity of the fabrication process together with high price 
of raw PTFE polymer renders the high cost of PTFE membranes. On the other hand, PVDF and PP membranes can be fabricated using phase separation methods, and thus they are advantageous over PTFE membranes with respects to material and manufacturing costs $[19,23]$. Nevertheless, PVDF and PP membranes are not comparable to PTFE membranes regarding to water flux, wetting resistance, and membrane stability.

MD polymer membranes can be prepared in either flat sheet or tubular forms with an isotropic, integral asymmetric, or composite structure [19, 23]. Isotropic membranes have a uniform structure across their entire cross-section, whereas integral asymmetric membranes are composed of a thin active layer with fine pores on the top of a more open structure supporting layer. Both layers of the integral asymmetric membranes are made from the same polymer. On the other hand, the composite membranes are composed of layers having different structures and being made from different materials. The top layer of the integral asymmetric and composite membranes is the active layer that is responsible for salt-water separation functionality, whereas the supporting layers provide additional mechanical strength to the membranes [19, 23].

MD membrane modules can be arranged in plate-and-frame, spiral-wound, and hollow fiber configurations $[8,19,23]$. The plate-and-frame and spiral-wound modules use flat sheet membranes whereas the hollow fiber modules rely on hollow fiber membranes. The plate-andframe and spiral-wound membrane modules offer higher fluid mixing and turbulence; therefore, they suffer less from membrane fouling and polarization effects than the hollow fiber modules. However, the packing density of plate-and-frame and spiral-wound modules is considerably lower than that of the hollow fiber. The packing density of the plate-and-frame and spiral-wound modules ranges from 100 to $400 \mathrm{~m}^{2} / \mathrm{m}^{3}$ and 300 to $1000 \mathrm{~m}^{2} / \mathrm{m}^{3}$, respectively, whereas that value of the hollow fiber membrane modules can be as high as $9000 \mathrm{~m}^{2} / \mathrm{m}^{3}$ [23, 24]. High membrane module packing density increases the compactness and hence reduces the physical footprint of the MD process.

\subsection{MD membrane properties}

Membrane properties, including surface hydrophobicity, membrane thickness, porosity, pore size and pore tortuosity, exert profound influences on the performance parameters of the MD process such as water flux, salt rejection, and thermal efficiency. The relationship between water flux $(J)$ and membrane properties during the MD process is expressed in Eq. (1).

$$
J \propto \frac{\left\langle r^{\alpha}\right\rangle \times \varepsilon}{\tau \times \delta}
$$

where $r$ is the membrane average pore size, $\varepsilon$ is the membrane porosity, $\tau$ is the membrane tortuosity, and $\delta$ is the membrane thickness. Equation 1 reveals that thin membranes with large pore sizes, high porosity, and a low tortuosity favor high water flux of the MD process. The thickness and porosity also determine the membrane physical strength and the conductive heat transfer through the membrane (i.e. which is considered the heat loss in MD). Indeed, thicker membranes offer a higher physical strength and lower heat loss due to conduction. Thus, membranes with optimal thickness are used to balance between the desires for high water flux and high physical strength and process thermal efficiency.

Salt rejection is another key MD process performance indicator. Theoretically, the MD process can offer a complete salt rejection, and super pure distillate can be obtained from saline water feeds providing that all the membrane pores are dry. However, in practical MD applications, the membrane pores can be wetted, and liquid water and thus dissolved salts can 
penetrate through the membrane from the feed to the distillate, leading to the deterioration in distillate quality. The risk of membrane pore wetting is evaluated using liquid entry pressure $(L E P)$, which is calculated as:

$$
L E P=\frac{-2 B \times \lambda_{L} \times \cos \theta}{r_{\max }}
$$

where $B$ is a geometric factor representing the pore structure, $\gamma_{L}$ is the liquid surface tension, $\theta$ is the liquid-solid contact angle which reflects the membrane surface hydrophobicity, and $r_{\max }$ is the maximum membrane pore size. According to Lawson and Lloyd [7], membrane pores become wetted when the pressure difference between the liquid and vapor phases at the membrane pore entrance exceeds $L E P$ (Eq. 3).

$$
\Delta P_{\text {interface }}=P_{\text {liquid }}-P_{\text {vapor }}>L E P
$$

It is noteworthy that the membrane pore wetting propensity is dependent on both membrane properties (e.g. pore structure, pore sizes, and surface hydrophobicity) and operating conditions (e.g. hydrostatic pressure and contaminants that reduce liquid surface tension of the feed water). To achieve a high $L E P$, the MD membrane is desired to have high surface hydrophobicity (i.e. high $\theta$ ) and small pore size (i.e. $r_{\max }$ ). Organic contaminants, particularly oil and surfactants, in the feed water reduce the surface tension of water $\left(\gamma_{L}\right)$, and alter the surface hydrophobicity when they accumulate on the membrane surface, thus possibly rendering membrane pores wetted. As a result, feed water pre-treatment is required for the MD process with challenging feed waters that have high contents of organic matters [25].

\section{HEAT AND MASS TRANSFER IN MD}

The MD process involves three main steps: (1) the vaporization of aqueous solution at liquid-vapor interface in the feed channel, (2) the transfer of vapor through the membrane pores, and (3) the condensation of vapor into liquid distillate. As a result, in the MD process both heat and mass transfer occur simultaneously and are interconnected [26, 27]. Figure 3 outlines the simultaneous heat and mass transfer in DCMD.

\subsection{Heat transfer and temperature polarization}

MD is a non-isothermal separation process in which heat is taken away at the liquid-vapor interfaces on the feed and the permeate sides of the membrane. As a result, the temperatures at the liquid-vapor interfaces differ from those of the bulk feed and permeate streams, and thermal boundary layers are established on both sides of the membrane (Figure 3). This phenomenon is termed temperature polarization. Temperature polarization reduces the thermal driving force of the MD process; thus, it is deemed a drawback of MD [27 - 30]. More negative impacts of temperature polarization on MD performance are experienced when the system is operated at high feed concentration, high temperature, and low feed and permeate circulation rates [31]. Under extreme conditions, negative flux can occur as a result of temperature polarization [7]. Various methods such as using spacers, applying turbulent flow, and employing microwave irradiation can be used to mitigate the effect of temperature polarization on the MD process performance [30, 32, 33].

The magnitude of temperature polarization is evaluated using the temperature polarization coefficient $(\varphi)$. The MD process with severe temperature polarization has $\varphi$ approaching to zero, while a thermally well-designed process can achieve a $\varphi$ value close to unity. In the practical 
MD process, the value of $\varphi$ varies in the range from 0.4 to 0.7 depending on the process fluid dynamics [27]. The calculation of $\varphi$ for the DCMD process is demonstrated in Eq. (4) [7].

$$
\varphi=\frac{T_{m . f}-T_{m . p}}{T_{b . f}-T_{b . p}}
$$

Heat transfer in DCMD is divided into three regions: heat transfer from the feed bulk solution through the thermal boundary layer to the membrane surface, heat transfer through the membrane, and heat transfer from the membrane surface to the distillate. The heat transfer through the thermal boundary layers in the feed and distillate channels is similar, and composed of the convective heat transfer and the heat transfer caused by mass transfer through the layers. However, the contribution of the heat transfer due to mass transfer in the thermal boundary layers is negligible [34] and can be ignored $[7,8,26]$. The heat transfer through the membrane is composed of the conductive heat via the membrane and the latent heat associated with the transfer of vapor molecules through the membrane pores. The conductive heat does not contribute to the vaporization; thus, it is deemed the heat loss of the DCMD process. This heat loss can count for $20-50 \%$ of total heat transfer in DCMD [7, 24]. To assess the effectiveness of the MD process in utilizing heat, a thermal efficiency coefficient $(\Pi)$ is used. $\Pi$ is calculated as:

$$
\Pi=\frac{J \times \Delta H_{v}}{J \times \Delta H_{v}+\frac{k_{m}}{\delta} \times\left(T_{m . f}-T_{m . p}\right)}
$$

where $J \times \Delta H_{v}$ is the latent heat of evaporation associated with the vapor transfer and hence is the useful heat, and $\frac{k_{m}}{\delta} \times\left(T_{m . f}-T_{m . p}\right)$ is the conductive heat loss through the membrane. The useful heat is a function of the mass flux $(J)$, whereas the conductive heat loss depends on the membrane properties (e.g. thermal conductivity $k_{m}$ and membrane thickness $\delta$ ) and operating conditions (e.g. $T_{m . f}$ and $T_{m . p}$ ).

The heat transfer in other MD configurations varies from that in DCMD. As a stagnant air gap and a condensing foil are inserted between the membrane and the coolant fluid, the heat transfer through the air gap by conduction and by the movement of vapor must be considered. For the VMD configuration, the heat transfer by conduction through the membrane pores can be ignored because of the applied vacuum. In SGMD, sweeping gas is employed in the permeate side instead of the cooling distillate applied in DCMD. Thus, the heat transfer mechanism in SGMD is similar to that in DCMD.

In MD, the heat transfer through the boundary layers on either side of the membrane is the rate-controlling step [7]. Thus, it is important to evaluate the boundary layer heat transfer coefficients. Various empirical correlations are used to estimate boundary layer heat transfer coefficients in the MD literature. Selection of empirical correlations to describe the heat transfer in MD depends on various factors namely the flow regime, Reynolds number, concentration and fluid properties [35]. 


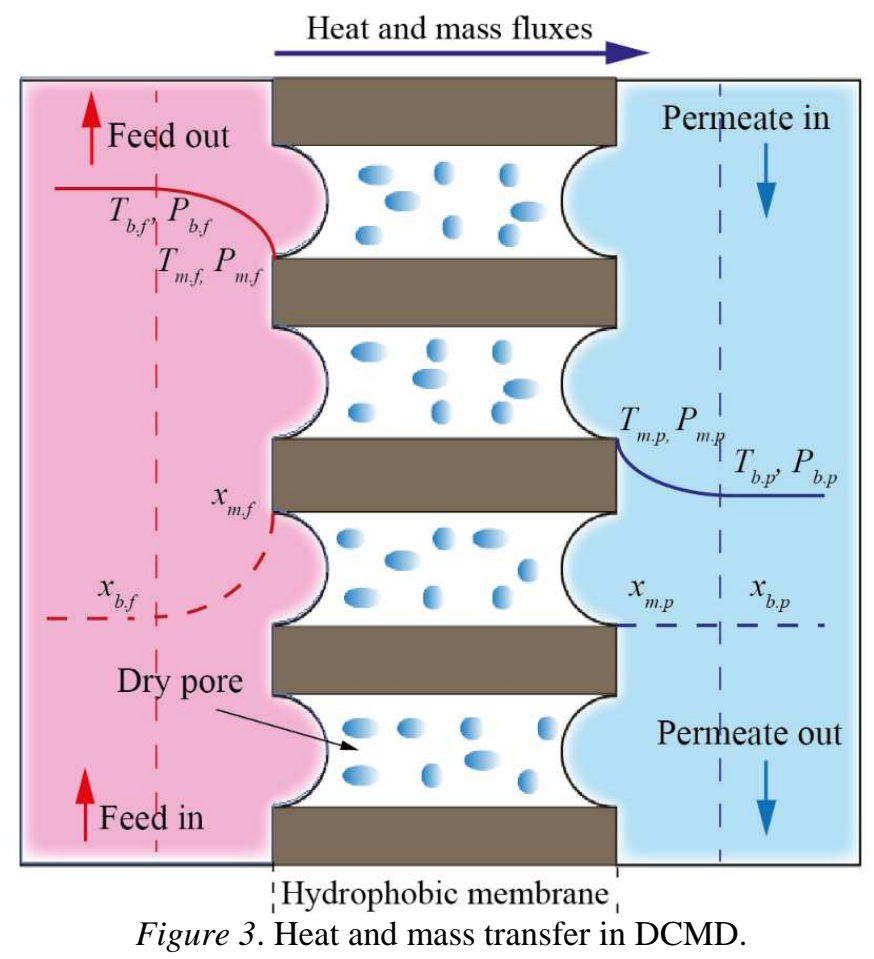

The heat transfer coefficients on the feed and permeate side of the membrane are calculated by:

$$
h=\frac{N u \times k}{d}
$$

where $h$ is the heat transfer coefficient, $N u$ is the Knudsen number calculated from empirical correlations, $k$ is the thermal conductivity of the feed and permeate fluid, and $d$ is the hydraulic diameter of the feed and permeate channels. The empirical correlations used to calculate the heat transfer coefficients through the boundary layers have the following form $[7,8]$ :

$$
N u=\text { Constant } \times \operatorname{Re}^{a} \times \operatorname{Pr}^{b}
$$

where $R e$ and $P r$ are Reynolds and Prandtl number, respectively. These numbers are calculated as:

$$
\begin{aligned}
& R e=\frac{v \times d \times \rho}{\mu} \\
& \operatorname{Pr}=\frac{C_{p} \times \mu}{k}
\end{aligned}
$$

where $v, \rho, \mu, C_{p}$, and $k$ respectively are cross flow velocity, density, viscosity, specific heat capacity, and thermal conductivity of the feed and permeate streams.

\subsection{Mass transfer and concentration polarization}

Like heat transfer, mass transfer (i.e. water transfer) in MD can be divided into three regions: across the feed boundary layer, through the membrane, and within the permeate stream. 
However, unlike what observed with heat transfer, overall mass transfer during the MD process is controlled by the mass transfer through the membrane.

The mass transfer through the MD membrane is proportional to the pressure difference between two sides of the membrane, and is given as:

$$
J=C_{m} \times\left(P_{m . f}-P_{m . p}\right)
$$

where $C_{m}$ is the membrane mass transfer coefficient, $P_{m . f}$ and $P_{m . p}$ are the water vapor pressures at the liquid-vapor interfaces on the feed and the permeate side of the membrane. The water vapor pressure of the process streams at temperature $T$ is calculated as followed:

$$
P_{(T)}=\exp \left(23.1964-\frac{3816.44}{T-46.13}\right) \times \chi_{\text {water }} \times a_{\text {water }}
$$

where $\chi_{\text {water }}$ is the molar fraction of water and $a_{\text {water }}$ is the water activity. For an aqueous saline solution, the water activity can be estimated by Eq. 12 [7]:

$$
a_{\text {water }}=1-0.5 \chi_{\text {salt }}-10 \chi_{\text {salt }}^{2}
$$

where $\chi_{\text {salt }}$ is the molar fraction of salt in the solution.

For an ideal dilute aqueous solution, Eq. (10) can be written as:

$$
J=C_{m} \times \frac{P^{0} \times \Delta H_{v}}{R \times T^{2}} \times \Delta T_{m}
$$

where $\Delta H_{v}$ is the latent heat of vaporization, $P^{0}$ and $T$ are the average water vapor pressure and temperature within the membrane pores, $\Delta T_{m}$ is the temperate difference between the feed and permeate sides of the membrane.

The calculation of $C_{m}$ involves empirical correlations. The selection of the empirical correlation to calculate $C_{m}$ is determined by mass transfer mechanisms occurring in the membrane pores. Employing the Dusty gas model to describe the mass transfer through the membrane, possible mass transfer mechanisms within membrane pores in MD are viscous flow, surface diffusion, Knudsen diffusion, and molecular diffusion. However, surface diffusion is often neglected in general MD applications [7]. Thus, depending on the structural properties of membrane, the properties of the transported vapor, and operating parameters, the predominant mass transfer mechanism can be viscous flow, Knudsen diffusion, molecular diffusion, or transition between them [24].

For seawater desalination by DCMD, $C_{m}$ can be described as $[8,34,36,37]$ :

$$
C_{m}=\left[\frac{3}{2} \frac{\tau \delta}{\varepsilon r}\left(\frac{\pi R T}{8 M}\right)^{1 / 2}+\frac{\tau \delta}{\varepsilon} \frac{P_{a}}{P D} \frac{R T}{M}\right]^{-1}
$$

where $\delta, \varepsilon, \tau$, and $r$ are the membrane thickness, porosity, pore tortuosity, and pore radius, respectively, $M$ is the molecular weight of water, $R$ is the gas constant (i.e. $8.314 \mathrm{~J} /(\mathrm{mol} . \mathrm{K})$ ), $T$ is the mean water vapor temperature $(\mathrm{K})$ inside the membrane pore, $P$ and $P_{a}$ are the total pressure and the air partial pressure $(\mathrm{Pa})$ inside the membrane pore, and $D$ is the water diffusion coefficient.

For seawater MD desalination, the transport of water vapor across the membrane from the feed to the distillate results in an increase in salt concentration in layers adjacent to the feed membrane surface, giving rise to a phenomenon termed concentration polarization. 
Concentration polarization renders the salt concentration at the feed membrane surface higher than that in the bulk feed solution (Figure 3), thus reducing water activity and hence water vapor pressure at the feed membrane surface. As a result, concentration polarization reduces water flux of the MD process. However, the influence of concentration polarization on water flux is negligible as compared to that of temperature polarization for MD desalination of seawater [8, $28,31]$. For the MD process of hyper saline feed waters, concentration polarization effect can greatly reduce water flux and increase the process propensity for membrane scaling [25]. The concentration polarization coefficient $\phi$ is used to quantify the concentration polarization. Given a nearly complete salt rejection of the MD membrane, $\phi$ of the seawater MD desalination process can be calculated as:

$$
\phi=\frac{x_{m . f}}{x_{b . f}}
$$

where $x_{b . f}$ and $x_{m . f}$ are the salt concentration in the feed bulk solution and at the feed membrane surface, respectively.

The calculation of the mass transfer (i.e. water flux) using the Eq. 10 involves the temperature and salt concentration at the membrane surfaces, hence it is impractical. Due to polarization effects, the temperature and salt concentration of the process solutions at the membrane surfaces differ from those in the bulk solutions, and it is unviable to measure them. Alternatively, water flux of the MD process can be calculated using properties of the bulk process streams as follow:

$$
J=K_{m} \times\left(P_{b . f}-P_{b . p}\right)
$$

where $K_{m}$ is the process mass transfer coefficient, $P_{b . f}$ and $P_{b . p}$ are respectively the water vapor pressure of the feed and permeate streams. $K_{m}$ depends on the membrane properties and operating conditions, and its value can be experimentally determined [38 - 40]. It is noteworthy that temperature and concentration polarization might be included in the experimental determination of $K_{m}$.

\subsection{Influences of operating conditions on MD water flux and thermal efficiency}

Main operating parameters of the MD process include feed temperature, permeate temperature, feed salinity, feed and permeate flow velocity, vacuum pressure, and air gap thickness.

Feed temperature is the most influential MD operating parameter with respect to process water flux and thermal efficiency. Elevating feed temperature leads to an exponential increase in water vapor pressure at the feed membrane surface, thus exponentially increasing water flux in all MD configurations. Increasing feed temperature also enhances thermal efficiency of the MD process; therefore, it is beneficial to operate the process at high feed temperature [41 - 45]. However, the temperature and concentration polarization effects become more severe with increased feed temperature [28, 43, 46]. Exacerbated polarization effects might lead to the formation of scales on the membrane surface that consequently deteriorates water flux and distillate quality of the seawater MD process.

Increasing permeate (or distillate) temperature on condition of constant feed temperature generally reduces the transmembrane vapor pressure difference, thus lowering water flux. However, the effect of permeate temperature on water flux varies for different MD configurations. In DCMD, an increase in water flux is observed when the permeate inlet 
temperature is reduced $[33,47,48]$. Indeed, it is noteworthy that the effect of reducing permeate temperature on water flux enhancement in DCMD is about 2-fold lower than that of increasing feed temperature [49]. On the other hand, the effect of permeate inlet temperature on water flux is negligible in AGMD and SGMD [50]. As a result, increasing feed temperature is preferable to decreasing permeate temperature for water flux improvement the MD process [26].

Feed salinity affects the heat and mass transfer during the seawater MD desalination process at various extents depending on the process operating water recovery (i.e. the volumetric ratio of the obtained distillate over the seawater feed). At low process water recoveries $(<50 \%)$, the influence of feed salinity on MD water flux and thermal efficiency is negligible $[38,51]$. This is because the transfer of water in MD is driven by the water vapor pressure difference across the membrane, and is not affected by the osmotic pressure of the seawater feed as observed in reverse osmosis (RO). At high water recoveries, the seawater feed is concentrated several times. At this such high feed salinity, the effect of concentration polarization becomes noticeable. Increased feed salinity reduces water activity and increases the feed viscosity at the membrane surface, hence leading to a decline in water flux [33, 51, $43-45]$. The thermal efficiency of the MD process also decreases at high feed salinity [41, 42].

Increasing the feed and permeate flow velocities improves the heat transfer coefficient in the feed and permeate channels, and reduces the concentration and temperature polarization effects, therefore increasing MD water flux. However, the effect of feed and permeate flow velocities on water flux is not as strong as that of feed temperature [49]. In addition, the feed flow velocity has a stronger impact on the water flux than the permeate flow velocity in the DCMD process. However, for the SGMD process, the influence of permeate flow (i.e. sweeping gas flow) velocity on water flux is more significant than that of the feed flow velocity. This is because in SGMD the mass flux is limited by the heat transfer through the sweep gas boundary layer [52] whereas in DCMD it is controlled by the heat transfer through the hot feed boundary layer [7].

The effect of permeate pressure (i.e. vacuum) on water flux and thermal efficiency is noticeable in VMD because the vapor transmembrane pressure difference is partially induced by applied vacuum in the permeate side. The permeate pressure in VMD might be the most effective parameter affecting the process water flux [53]. As the permeate pressure decreases, a higher driving force is induced; consequently, water flux increases linearly [32, 53-55]. However, decreasing permeate pressure to increase the flux also results in a reduction in selectivity in the VMD treatment of feed solution containing dissolved organics [55]. It is worth noting that decreasing permeate pressure also induces a higher transmembrane hydrostatic pressure, hence posing a higher risk of membrane pore wetting [36].

The air gap between the membrane and the condenser in AGMD mitigates the conductive heat loss through the membrane but increases the resistance to mass transfer in the permeate side of the membrane. Thus, the air gap thickness influences both water flux and thermal efficiency of the AGMD process. Lawson and Lloyd [7] observed a sharp decrease in water flux when the air gap thickness increased to $1 \mathrm{~mm}$, then water flux slightly decreased as the air gap thickness reached $5 \mathrm{~mm}$. The authors also reported a significant conductive heat loss with air gap thickness below $0.4 \mathrm{~mm}$. Thus, optimal air gap thickness was recommended to balance water flux and thermal efficiency. 


\subsection{Approaches to enhance water flux in MD}

Key factors affecting MD water flux are: (1) the membrane active surface for water evaporation; (2) the driving force induced by the transmembrane temperature difference; (3) the resistance to mass transfer [56]. The membrane active surface for water evaporation is a function of membrane porosity, and hence is difficult to be improved due to the required membrane mechanical strength. Thus, approaches to enhancing water flux are largely focused on maximizing the driving force and minimizing the mass transfer resistance.

The difference between the temperatures at the liquid-vapor interfaces in the hot and cold side of the membrane is the driving force of the MD process. Temperature polarization lowers the driving force. As a result, to increase water flux the convective heat transfer coefficients in boundary layers need improved to mitigate the temperature polarization [57]. The convective heat transfer coefficients are inversely proportional to the boundary layer thickness. Thus, the convective heat transfer coefficients can be improved by promoting the stream turbulence and flow rate to reduce the boundary layer thickness.

Employing spacers in MD channels to promote the stream turbulence is an effective method to increase water flux. Phattaranawik et al. [29, 30] employed spacers with various characteristics in the feed and distillate channels of a DCMD system. Temperature polarization was found to approach utility and the system water flux was increased by $60 \%$ with the spacers used. Martinez-Diez et al. [58] also confirmed the effects of spacers on MD water flux. Turbulence caused by spacers led to the decreased temperature polarization and the enhanced mass flux. Moreover, Yun et al. [33] declared that the flux enhancement effect of the spacer in the feed channel was higher than that in the distillate channel.

Gas bubbling was also incorporated into the MD process to enhance its performance. By introducing gas bubbles to the feed channel of a DCMD process, Chen et al. [46] observed an increase in the water flux up to $26 \%$ in comparison with that of the non-gas bubbling assisted process. They attributed the water flux improvement to the lowered temperature and concentration polarization due to intensified local mixing and flow disturbance in the feed boundary layer [46]. Moreover, the positive impact of gas bubbling on the MD performance was found more significant at high feed temperature [46].

Using roughened-surface channel to increase MD water productivity in seawater desalination was proposed by Ho et al. [59]. By integrating a rough plate in the feed channel and spacers into the DCMD module, heat transfer in the feed channel was enhanced resulting in an increase of $37 \%$ in water production. However, roughened-surface channel also led to the increase in energy consumption of the system. Thus, an optimum roughness of the feed channel surface was experimentally determined [59].

Employing microwave irradiation was also recommended for MD water flux enhancement. Ji et al. [32] investigated the performance of a VMD system equipped with a microwave source. They found that the mass transfer process of VMD was significantly improved because of applying microwave irradiation. Moreover, the effects of microwave irradiation on water flux enhancement were found to be more significant at low feed temperature, low feed velocity and low vacuum pressure [32]. However, the membrane scaling caused by the deposition of calcium was intensified by microwave irradiation [32].

MD water flux enhancement was also achieved by using fabricated polymeric membranes having higher hydrophobicity. Dumee et al. [60] investigated the performance of commercial membranes and the hydrophobicity-enhanced fabricated membranes with similar geometrical 
properties. Higher flux was obtained with the fabricated membranes in comparison to the commercial membranes. The positive influence of increased membrane hydrophobicity to MD flux enhancement was also confirmed by Bonyadi and Chung [61]. Thus, employing fabricated membrane with high hydrophobicity might be a feasible approach to the MD water flux improvement.

\section{POTENTIAL OF MD FOR SEAWATER DESALINATION APPLICATIONS IN VIETNAM}

MD embodies several prominent features that make it a promising candidate for seawater desalination applications, particularly for remote coastal areas and islands in Vietnam. As a thermally driven process, water flux in MD is negligibly affected by the feed osmotic pressure as compared with other pressure-driven membrane desalination processes (e.g. RO and nanofiltration (NF)). As a result, the MD process can concentrate the seawater feed up to the saturation limits of salts in the seawater feed. Given this capability, MD has been employed as a stand-alone seawater desalination process, or combined with a seawater RO desalination process to improve the process water recoveries and minimize the RO brine volume.

MD can offer a cost-effective technology platform to seawater desalination application in Vietnam. The MD process does not involve high hydrostatic pressure to achieve salt-water separation as required in RO and NF; therefore, MD systems can be made from inexpensive non-corrosive materials (e.g. plastics and aluminium alloys) to reduce the process investment costs. The absence of high hydrostatic pressure together with the discontinuity of the liquid phase across the membrane renders the MD process much less prone to membrane fouling than RO and NF. As a result, the seawater MD desalination process can be sustainably operated with little seawater feed pre-treatment (e.g. sand filtration or cartridge filtration) without any membrane fouling issues. Indeed, Duong et al. [38] have demonstrated that the seawater MD desalination process could be sustainably operated at a water recovery of $70 \%$ without any observable membrane fouling or scaling when actual raw seawater feed was pre-filtered by 0.45 $\mu \mathrm{m}$ filter paper. The MD process also inherits typical attributes of membrane processes, including modulation, compactness, and process efficiency; therefore, it requires significantly less physical and energy footprints as compared to conventional thermal distillation (e.g. multistage flash (MSF) and multi-effect distillation (MED)). Finally, the primary energy input to the MD process is heat at mild temperatures (i.e. ranging from 40 to $80^{\circ} \mathrm{C}$ ). Low-grade heat such as waste heat or solar thermal energy can be sourced to meet the energy demand of the MD process, leading to noticeable process energy cost savings [62]. As a result, MD can be an ideal replacement for RO or MSF and MED in the desalination applications which require a low-cost and maintenance-free process.

Given the above-mentioned attributes, MD can be an ideal technology platform for smallscale seawater desalination applications in Vietnam. With more than $3000 \mathrm{~km}$ of coastline and great numbers of islands, Vietnam is in a great need for small-scale, de-centralized, stand-alone, and low maintenance or maintenance-free desalination systems that can provide drinking water at affordable cost directly from seawater. Given their low investment and operational costs, MD systems can be deployed to provide fresh water to people and military personnel in coastal areas or on islands, such as Spratly Islands. Small-scale MD systems can also be installed on fishing boats to meet drinking water demand of the fishermen on the boats. The waste heat from the boat engine can be utilized to supply the thermal energy demand to the MD system. With an MD system on boats, lack of fresh water will no longer be a concern for long-travelled fishermen. 


\section{CHALLENGES TO SEAWATER MD DESALINATION}

\subsection{Membrane pore wetting}

One vital requirement for the seawater MD desalination process is the non-wettability of the membrane pores. To achieve a complete salt rejection, only water vapour is allowed to transfer through the membrane pores, and the pores must be in dry condition. Under certain conditions, liquid water can penetrate the membrane pores and render them wet. When the membrane pores are wetted, the membrane active surface area for water evaporation is reduced, leading to decline in the process water flux. In addition, the penetration of liquid saline water through the wetted membrane pores reduces the salt rejection of the membrane, and hence deteriorates the quality of the MD water product (Figure 4).

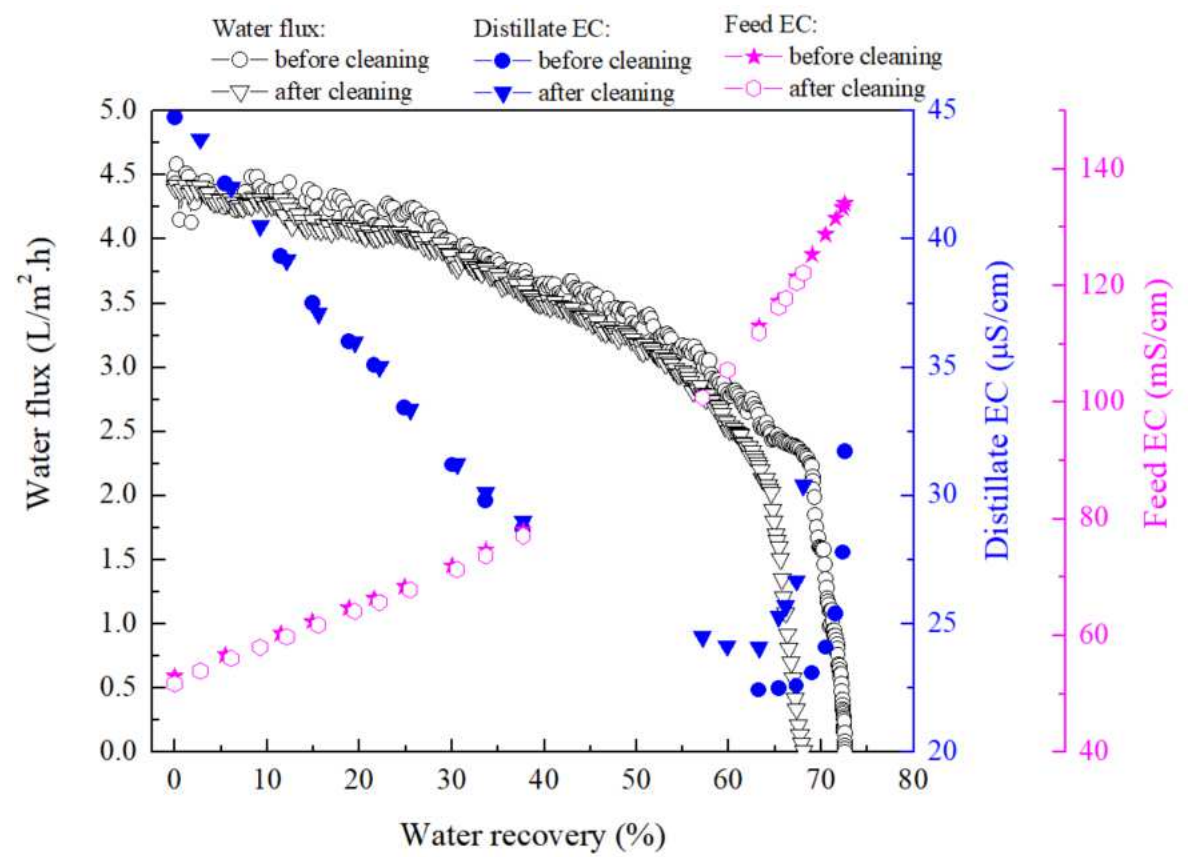

Figure 4. Changes in water flux and distillate quality (i.e. distillate electrical conductivity) when the membrane pores are wetted due to membrane scaling in a AGMD process with actual seawater feed (from [39]).

Factors that can lead to membrane pore wetting during the MD process are the deposition of contaminants in the feed water on the membrane surface and the resultant degradation of the membrane. As implied in the Eq. 2, a higher $L E P$ value can be achieved when using a more hydrophobic membrane (i.e. $\theta>90^{\circ}$ ) with the feed solution having a high surface tension $\left(\lambda_{L}\right)$. Most membranes used in MD have water-membrane contact angle in the range from $120^{\circ}$ to $130^{\circ}$ [63], and fabricated surface-modified membranes with water-membrane contact angle as high as $160^{\circ}$ and $178^{\circ}$ have been proposed for the MD process for desalination applications [64, 65]. Contaminants depositing on the membrane surface can alter its hydrophobicity, thus reducing $L E P$ and increasing the risk of membrane pore wetting. Moreover, organic contaminants such as surfactants and detergents can greatly reduce the surface tension of the feed water [66], leading to further reduction in $L E P$. 


\subsection{Membrane fouling and scaling}

Membrane fouling is a major hindrance to the commercialization of MD for water treatment and desalination [67, 68]. Fouling reduces permeability, shortens the lifetime of membranes, and increases energy consumption. Consequently, membrane fouling raises the operational costs of the MD process. The investment cost of the MD process is also increased because of additional pre-treatment facilities and chemicals required to prevent and control fouling $[67,69]$.

Membrane fouling in MD is defined as the accumulation of undesirable deposits onto the membrane surface or into the membrane pores leading to a decline of membrane efficiency [70, 71]. The formation of unwanted materials adds extra resistance to the total mass transfer resistance of the MD process. The undesirable deposits might be particulates, gels formed by organic substances, precipitated crystals of sparingly soluble salts, and biofilm formed by microorganisms. Membrane fouling is categorized into four types, namely colloidal fouling, organic fouling, scaling, and biofouling according to the nature of particles that induce fouling. Amongst these types, organic fouling and scaling are the most prevalent in seawater MD desalination applications [70, 71].

Organic fouling is a result of the adsorption of dissolved organic substances such as oil, macromolecules, proteins, humic acids onto the membrane surface. The accumulation of these organic matters on the membrane surface leads to a decline in membrane permeability. It is worth mentioning that despite their low concentration in the feed water, organic foulants often cause severe declines in MD water flux because they can form complexation with calcium scales in the feed water [72, 73]. Moreover, hydrophobic MD membranes are more prone to organic fouling due to hydrophobic adsorption of organic materials to the membrane surface $[72,74]$.

Scaling (or inorganic fouling) in the MD process is caused by the precipitation of sparingly soluble salts at their super-saturation state. The most likely scalants faced in MD desalination are calcium sulfate $\left(\mathrm{CaSO}_{4}\right)$, calcium carbonate $\left(\mathrm{CaCO}_{3}\right)$, and silicate $[14,39,75]$. These scalants have limited and temperature-inverse solubility (except silicate) in the MD operating temperature range [76]. During the MD process, when water is extracted from the feed solution, the concentrations of the sparingly soluble salts in the feed channel increase and might reach super-saturation, posing a high risk of scaling. The scale formation on the membrane can constrain the MD desalination process from achieving high water recovery ratios [51,77].

MD operating parameters exert great effects on the scale formation rate and the scale morphology. Gryta [78] reported that increasing feed temperature resulted in a higher rate of the carbonate scale formation, and low feed flow velocity led to a more compact deposit layer on the membrane. A similar trend was observed in the study of Wang et al. [56]. Nghiem and Cath [68] observed more severe scale formation of $\mathrm{CaSO}_{4}$ than that of $\mathrm{CaCO}_{3}$ and silicate, and they also found that increased feed temperature and $\mathrm{CaSO}_{4}$ concentration led to a decrease in the induction time and an increase in the $\mathrm{CaSO}_{4}$ crystal size. He et al. [77] declared that the co-precipitation of $\mathrm{CaCO}_{3}$ and $\mathrm{CaSO}_{4}$ formed more adherent and tenacious deposit layers on the membrane than those consisted of single salts. Duong et al. [39] confirmed the uneven distribution of scale layers and salt crystal morphologies on the membrane surface due to the variation in stream temperatures along the channels of the AGMD module (Figure 5).

The scale formation on the membrane in MD is also influenced by the temperature and concentration polarization effects. Due to the polarization effect, concentrations of the sparingly soluble salts in the boundary layer adjacent to the membrane are higher than those in the bulk feed solution, hence increasing the scale formation tendency [56. 76. 79]. In contrast, the 
temperature polarization effect reduces the temperature of the feed solution next to the membrane, and might increase the solubility of sparingly soluble calcium salts; therefore, it lowers potential for the scale formation. However, the influence of the temperature polarization effect on the scale formation is trivial in comparison with that of the concentration polarization effect $[76,77]$. It is noteworthy that unlike sparingly soluble calcium salts, silica has solubility proportional to temperature, thus temperature polarization tends to raise the deposition of silica on the membrane surface [80].
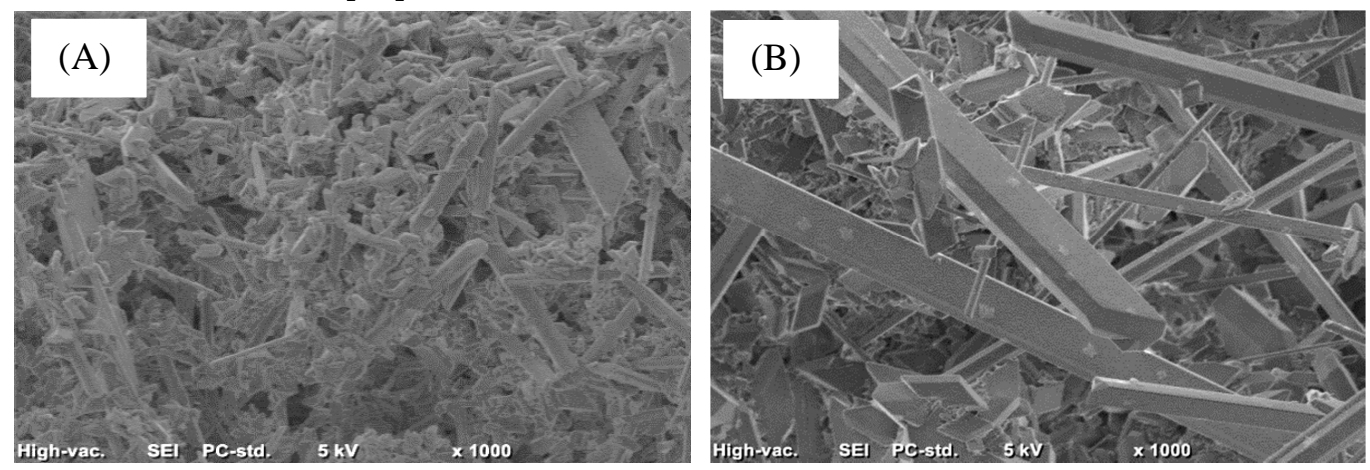

Figure 5. Morphologies of scale layers during the AGMD process of seawater at feed and coolant temperatures of (A) $35 / 25^{\circ} \mathrm{C}$ and (B) $60 / 50{ }^{\circ} \mathrm{C}$ (from [39]).

\subsection{Thermal efficiency and energy consumption}

Together with membrane scaling, intensive energy consumption has been considered a hindrance to the realization of MD for seawater desalination applications. As a phase-change separation process, MD consumes huge amount of thermal energy (i.e. heating and cooling) to facilitate the phase conversion of water from liquid to vapor and vice versa. The transfer of the latent heat that is associated with the transfer of water coincides with the heat conduction through the membrane during the MD process. The heat conduction through the membrane, which is the heat loss, can account for up to $50 \%$ of the total heat input of the MD process [7]. As a result, most MD processes reported in the literature demonstrate poor energy efficiency with specific energy consumption of several orders of magnitude higher than that of $\mathrm{RO}[9,36$, 81].

Specific thermal energy consumption (STEC) is commonly used to evaluate the performance of the seawater MD desalination process with respect to thermal efficiency. It is noteworthy that STEC of MD processes reported in the literature is widely dispersed as recently highlighted by Khayet [82]. The STEC of the MD process can differ in 3 orders of magnitude, ranging from as low as 1 up to $9,000 \mathrm{kWh} / \mathrm{m}^{3}$ [82]. The wide dispersion in STEC values is attributed to the variation in the configuration, membrane module geometry, and operating conditions of the MD process [82]. As a notable example, Carlsson [83] reported a very low STEC of $1.25 \mathrm{kWh} / \mathrm{m}^{3}$, but failed to provide any analytical details and operating parameters of the MD process used in his study. Koschikowski et al. [11] reported a STEC value of 117 $\mathrm{kWh} / \mathrm{m}^{3}$ for an MD system with an $8 \mathrm{~m}^{2}$ spiral-wound AGMD membrane module at $75{ }^{\circ} \mathrm{C}$ evaporator inlet temperature and $350 \mathrm{~L} / \mathrm{h}$ water flow rate. A larger AGMD system (i.e. with membrane area of $40 \mathrm{~m}^{2}$ ) exhibited a higher $S T E C$ value ranging from 200 to $300 \mathrm{kWh} / \mathrm{m}^{3}$ [84]. Much higher STEC values were reported for the MD processes using DCMD configuration. Of a particular note, Criscuoli et al. [85] demonstrated a DCMD process with really high STEC values ranging from 3500 to $4580 \mathrm{kWh} / \mathrm{m}^{3}$. 
Thermal efficiency of the MD process can be significantly enhanced, and thus the process $S T E C$ can be reduced by recovering the latent heat associated with the water vapour transfer. In AGMD, the recovery of the latent heat can be achieved inside the membrane module. The feed water can be fed to the coolant channel to act as a coolant fluid, and in tandem to be preheated by the latent heat of water vapour condensation. Then, the preheated feed water can be additionally heated by an external heat source to reach a desired temperature prior to entering the feed channel of the AGMD membrane module. Thus, STEC of the AGMD process can be noticeably reduced. Operating conditions, including feed inlet temperature, feed salinity, and particularly water circulation rate, are expected to exert strong influences on the STEC of the AGMD process. Indeed, Duong et al. [13] have demonstrated a pilot single-pass seawater AGMD desalination process with a minimum $S T E C$ of $90 \mathrm{kWh} / \mathrm{m}^{3}$, and the process water circulation rate was found to be the most influential operating factor affecting the water flux and thermal efficiency of the pilot process.

Unlike in AGMD, in DCMD the heat recovery can be achieved using an external heat exchanger [86]. The latent heat accumulated in the distillate stream is recovered to preheat the feed stream in the heat exchanger. When the heat exchanger is coupled with the DCMD membrane module, the relative flow rate between the feed and the distillate stream and the surface areas of the heat exchanger and the membrane module strongly determine the process STEC [86]. The DCMD process obtains minimum STEC at a critical relative flow rate and with infinite heat exchanger and membrane module surfaces [86]. In practice, however, it is unfeasible to have heat exchanger and membrane module with infinite surfaces.

Thermal efficiency of the DCMD process can also be improved by brine recycling [38]. In the DCMD process, particularly for the small-scale system with short membrane channels, the warm brine leaving the membrane module contains a considerable amount of sensible heat. When the brine is recycled in the process, the brine sensible heat can be utilised, hence reducing the total heat demand and STEC of the process. Brine recycling also helps enhance the utilisation of the available membrane surface area to increase the water recovery ratio of the DCMD process. Indeed, Saffarini et al. [87] have suggested brine recycling for MD thermal efficiency improvement. A major challenge to brine recycling in seawater DCMD desalination is to manage the negative influence of membrane scaling and increased feed salinity on the water flux and salt rejection of the process. Thus, Duong et al. [38] have experimentally optimized the DCMD desalination process with an actual seawater feed under brine-recycling operation mode. The experimental results revealed an optimal process water recovery ranging from $30 \%$ to $60 \%$. Within the optimal water recovery range, the influence of increased feed salinity on water flux was negligible, no membrane scaling occurred, and the process could obtain a virtually complete salt rejection. Most importantly, the STEC of the process under brine-recycling operation was reduced more than half when operated in the optimal water recovery range [38].

\section{CONCLUSIONS}

Seawater desalination using membrane distillation (MD) can be a pragmatic solution to fresh water scarcity in Vietnam. As a hybrid desalination process, MD inherits attributes of both pressure-driven membrane separation and thermal distillation. These attributes include process modularization, low susceptibility to feed osmotic pressure, low risk of membrane fouling and thus negligible feed water pre-treatment required, and low investment and operational costs. In this paper, a comprehensive review of the seawater MD desalination process was provided. The basics of the MD process (e.g. configurations, membrane modules, membrane properties, and 
heat and mass transfer mechanisms), the influences of operating conditions, and the approaches to enhance the process performance were first reviewed and discussed. The great potential of the MD process for seawater desalination application in Vietnam was delineated. The technical challenges to the realization of the seawater MD desalination process were also pointed out. Through the analyses and discussions provided in this review paper, the viability of MD for fresh water provision in remote coastal areas in Vietnam can be shed light on.

\section{REFERENCES}

1. World Bank - Social Republic of Vietnam: Review of urban water and wastewater utility reform and regulation, 2014.

2. Özdemir S., Elliott M., Brown J., Nam P. K., Hien V. T., and Sobsey M. D. - Rainwater harvesting practices and attitudes in the mekong delta of Vietnam, Journal of Water Sanitation and Hygiene for Development 1 (2011) 171-177.

3. Agusa T., Trang P. T. K., Lan V. M., Anh D. H., Tanabe S., Viet P. H., and Berg M. Human exposure to arsenic from drinking water in Vietnam, Science of The Total Environment 488-489 (2014) 562-569.

4. Elimelech M. and Phillip W. A. - The Future of Seawater Desalination: Energy, Technology, and the Environment, Science 333 (2011) 712-717.

5. Likhachev D. S. and Li F. C. - Large-scale water desalination methods: A review and new perspectives, Desalination and Water Treatment 51 (2013) 2836-2849.

6. Khawaji A. D., Kutubkhanah I. K., and Wie J. M. - Advances in seawater desalination technologies, Desalination 221 (2008) 47-69.

7. Lawson K. W. and Lloyd D. R. - Membrane distillation, Journal of Membrane Science 124 (1997) 1-25.

8. Alkhudhiri A., Darwish N., and Hilal N. - Membrane distillation: A comprehensive review, Desalination 287 (2012) 2-18.

9. Zaragoza G., Ruiz-Aguirre A., and Guillén-Burrieza E. - Efficiency in the use of solar thermal energy of small membrane desalination systems for decentralized water production, Applied Energy 130 (2014) 491-499.

10. Chafidz A., Al-Zahrani S., Al-Otaibi M. N., Hoong C. F., Lai T. F., and Prabu M. Portable and integrated solar-driven desalination system using membrane distillation for arid remote areas in Saudi Arabia, Desalination 345 (2014) 36-49.

11. Koschikowski J., Wieghaus M., and Rommel M. - Solar thermal-driven desalination plants based on membrane distillation, Desalination 156 (2003) 295-304.

12. Ghaffour N., Bundschuh J., Mahmoudi H., and Goosen M.F.A. - Renewable energydriven desalination technologies: A comprehensive review on challenges and potential applications of integrated systems, Desalination 356 (2015) 94-114.

13. Duong H. C., Cooper P., Nelemans B., Cath T. Y., and Nghiem L. D. - Evaluating energy consumption of membrane distillation for seawater desalination using a pilot air gap system, Separation and Purification Technology 166 (2016) 55-62.

14. Duong H. C., Chivas A. R., Nelemans B., Duke M., Gray S., Cath T. Y., and Nghiem L. D. - Treatment of RO brine from CSG produced water by spiral-wound air gap membrane distillation - A pilot study, Desalination 366 (2015) 121-129. 
15. Koo J., Han J., Sohn J., Lee S., and Hwang T. M. - Experimental comparison of direct contact membrane distillation (DCMD) with vacuum membrane distillation (VMD), Desalination and Water Treatment 51 (2013) 6299-6309.

16. Cath T. Y., Adams V. D., and Childress A. E. - Experimental study of desalination using direct contact membrane distillation: a new approach to flux enhancement, Journal of Membrane Science 228 (2004) 5-16.

17. Winter D., Koschikowski J., and Ripperger S. - Desalination using membrane distillation: Flux enhancement by feed water deaeration on spiral-wound modules, Journal of Membrane Science 423-424 (2012) 215-224.

18. Winter D., Koschikowski J., and Wieghaus M. - Desalination using membrane distillation: Experimental studies on full scale spiral wound modules, Journal of Membrane Science 375 (2011) 104-112.

19. Wang P. and Chung T. S. - Recent advances in membrane distillation processes: Membrane development, configuration design and application exploring, Journal of Membrane Science 474 (2015) 39-56.

20. Xing Y., Qi C., Feng H., Lv Q., Xu G., Lv H., and Wang X. - Performance study of a pilot-scale multi-effect vacuum membrane distillation desalination plant, Desalination $\mathbf{4 0 3}$ (2017) 199-207.

21. Mohamed E.S., Boutikos P., Mathioulakis E., and Belessiotis V. - Experimental evaluation of the performance and energy efficiency of a Vacuum Multi-Effect Membrane Distillation system, Desalination 408 (2017) 70-80.

22. Boutikos P., Mohamed E.S., Mathioulakis E., and Belessiotis V. - A theoretical approach of a vacuum multi-effect membrane distillation system, Desalination 422 (2017) 25-41.

23. Eykens L., De Sitter K., Dotremont C., Pinoy L., and Van der Bruggen B. - Membrane synthesis for membrane distillation: A review, Separation and Purification Technology 182 (2017) 36-51.

24. Curcio E. and Drioli E. - Membrane distillation and related operations - A review, Separation and Purification Reviews 34 (2005) 35-86.

25. Duong H. C. and Nghiem L. D. - 4.8 New Membrane Distillation Integrated Systems, in Comprehensive Membrane Science and Engineering (Second Edition), Elsevier: Oxford, 2017, 150-163.

26. El-Bourawi M. S., Ding Z., Ma R., and Khayet M. - A framework for better understanding membrane distillation separation process, Journal of Membrane Science 285 (2006) 4-29.

27. Phattaranawik J. and Jiraratananon R. - Direct contact membrane distillation: effect of mass transfer on heat transfer, Journal of Membrane Science 188 (2001) 137-143.

28. Phattaranawik J., Jiraratananon R., and Fane A. G. - Heat transport and membrane distillation coefficients in direct contact membrane distillation, Journal of Membrane Science 212 (2003) 177-193.

29. Phattaranawik J., Jiraratananon R., and Fane A. G. - Effects of net-type spacers on heat and mass transfer in direct contact membrane distillation and comparison with ultrafiltration studies, Journal of Membrane Science 217 (2003) 193-206. 
30. Phattaranawik J., Jiraratananon R., Fane A. G., and Halim C. - Mass flux enhancement using spacer filled channels in direct contact membrane distillation, Journal of Membrane Science 187 (2001) 193-201.

31. Termpiyakul P., Jiraratananon R., and Srisurichan S. - Heat and mass transfer characteristics of a direct contact membrane distillation process for desalination, Desalination 177 (2005) 133-141.

32. Ji Z., Wang J., Hou D., Yin Z., and Luan Z. - Effect of microwave irradiation on vacuum membrane distillation, Journal of Membrane Science 429 (2013) 473-479.

33. Yun Y., Wang J., Ma R., and Fane A.G. - Effects of channel spacers on direct contact membrane distillation, Desalination and Water Treatment 34 (2011) 63-69.

34. Qtaishat M., Matsuura T., Kruczek B., and Khayet M. - Heat and mass transfer analysis in direct contact membrane distillation, Desalination 219 (2008) 272-292.

35. Andrjesdóttir Ó., Ong C. L., Nabavi M., Paredes S., Khalil A. S. G., Michel B., and Poulikakos D. - An experimentally optimized model for heat and mass transfer in direct contact membrane distillation, International Journal of Heat and Mass Transfer 66 (2013) 855-867.

36. Shim W. G., He K., Gray S., and Moon I.S. - Solar energy assisted direct contact membrane distillation (DCMD) process for seawater desalination, Separation and Purification Technology 143 (2015) 94-104.

37. Zhang J., Gray S., and Li J. D. - Modelling heat and mass transfers in DCMD using compressible membranes, Journal of Membrane Science 387-388 (2012) 7-16.

38. Duong H. C., Cooper P., Nelemans B., and Nghiem L. D. - Optimising thermal efficiency of direct contact membrane distillation via brine recycling for small-scale seawater desalination, Desalination 374 (2015) 1-9.

39. Duong H. C., Duke M., Gray S., Cooper P., and Nghiem L. D. - Membrane scaling and prevention techniques during seawater desalination by air gap membrane distillation, Desalination 397 (2016) 92-100.

40. Duong H.C., Hai F. I., Al-Jubainawi A., Ma Z., He T., and Nghiem L. D. - Liquid desiccant lithium chloride regeneration by membrane distillation for air conditioning, Separation and Purification Technology 177 (2017) 121-128.

41. Al-Obaidani S., Curcio E., Macedonio F., Di Profio G., Al-Hinai H., and Drioli E. Potential of membrane distillation in seawater desalination: Thermal efficiency, sensitivity study and cost estimation, Journal of Membrane Science 323 (2008) 85-98.

42. Guillén-Burrieza E., Zaragoza G., Miralles-Cuevas S., and Blanco J. - Experimental evaluation of two pilot-scale membrane distillation modules used for solar desalination, Journal of Membrane Science 409-410 (2012) 264-275.

43. Ali A., Macedonio F., Drioli E., Aljlil S., and Alharbi O. A. - Experimental and theoretical evaluation of temperature polarization phenomenon in direct contact membrane distillation, Chemical Engineering Research and Design 91 (2013) 1966-1977.

44. Martínez-Díez L., Florido-Díaz F. J., and Vázquez-González M. I. - Study of evaporation efficiency in membrane distillation, Desalination 126 (1999) 193-198. 
45. Bahmanyar A., Asghari M., and Khoobi N. - Numerical simulation and theoretical study on simultaneously effects of operating parameters in direct contact membrane distillation, Chemical Engineering and Processing: Process Intensification 61 (2012) 42-50.

46. Chen G., Yang X., Wang R., and Fane A. G. - Performance enhancement and scaling control with gas bubbling in direct contact membrane distillation, Desalination 308 (2013) 47-55.

47. Laganà F., Barbieri G., and Drioli E. - Direct contact membrane distillation: modelling and concentration experiments, Journal of Membrane Science 166 (2000) 1-11.

48. Lawson K. W. and Lloyd D. R. - Membrane distillation. II. Direct contact MD, Journal of Membrane Science 120 (1996) 123-133.

49. Alklaibi A. M. and Lior N. - Membrane-distillation desalination: Status and potential, Desalination 171 (2005) 111-131.

50. Banat F.A. and Simandl J. - Membrane distillation for dilute ethanol: Separation from aqueous streams, Journal of Membrane Science 163 (1999) 333-348.

51. Nghiem L. D., Hildinger F., Hai F. I., and Cath T. - Treatment of saline aqueous solutions using direct contact membrane distillation, Desalination and Water Treatment 32 (2011) 234-241.

52. Khayet M., Godino M. P., and Mengual J. I. - Thermal boundary layers in sweeping gas membrane distillation processes, AIChE Journal 48 (2002) 1488-1497.

53. Chiam C.K. and Sarbatly R. - Vacuum membrane distillation processes for aqueous solution treatment - A review, Chemical Engineering and Processing: Process Intensification 74 (2013) 27-54.

54. Mericq J. P., Laborie S., and Cabassud C. - Vacuum membrane distillation of seawater reverse osmosis brines, Water Research 44 (2010) 5260-5273.

55. Banat F.A. and Simandl J. - Removal of benzene traces from contaminated water by vacuum membrane distillation, Chemical Engineering Science 51 (1996) 1257-1265.

56. Wang L., Li B., Gao X., Wang Q., Lu J., Wang Y., and Wang S. - Study of membrane fouling in cross-flow vacuum membrane distillation, Separation and Purification Technology 122 (2014) 133-143.

57. Camacho L.M., Dumée L., Jianhua Z., Jun-de L., Duke M., Gomez J., and Gray S. Advances in membrane distillation for water desalination and purification applications, Water 5 (2013) 94-196.

58. Martínez-Díez L., Vázquez-González M. I., and Florido-Díaz F. J. - Study of membrane distillation using channel spacers, Journal of Membrane Science 144 (1998) 45-56.

59. Ho C., Chang H., Chang C., and Huang C. - Theoretical and experimental studies of flux enhancement with roughened surface in direct contact membrane distillation desalination, Journal of Membrane Science 433 (2013) 160-166.

60. Dumée L. F., Gray S., Duke M., Sears K., Schütz J., and Finn N. - The role of membrane surface energy on direct contact membrane distillation performance, Desalination $\mathbf{3 2 3}$ (2013) 22-30.

61. Bonyadi S. and Chung T. S. - Flux enhancement in membrane distillation by fabrication of dual layer hydrophilic-hydrophobic hollow fiber membranes, Journal of Membrane Science 306 (2007) 134-146. 
62. Duong H. C., Xia L., Ma Z., Cooper P., Ela W., and Nghiem L. D. - Assessing the performance of solar thermal driven membrane distillation for seawater desalination by computer simulation, Journal of Membrane Science 542 (2017) 133-142.

63. Zhu H., Wang H., Wang F., Guo Y., Zhang H., and Chen J. - Preparation and properties of PTFE hollow fiber membranes for desalination through vacuum membrane distillation, Journal of Membrane Science 446 (2013) 145-153.

64. Cerneaux S., Strużyńska I., Kujawski W. M., Persin M., and Larbot A. - Comparison of various membrane distillation methods for desalination using hydrophobic ceramic membranes, Journal of Membrane Science 337 (2009) 55-60.

65. Khemakhem S. and Amar R. B. - Grafting of fluoroalkylsilanes on microfiltration Tunisian clay membrane, Ceramics International 37 (2011) 3323-3328.

66. Franken A. C. M., Nafey J. A. M., Mulder M. H. V., Bargeman D., and Smolders C. A. Wetting criteria for the applicability of membrane distillation, Journal of Membrane Science 33 (1987) 315-328.

67. Alhseinat E. and Sheikholeslami R. - A completely theoretical approach for assessing fouling propensity along a full-scale reverse osmosis process, Desalination 301 (2012) 19.

68. Nghiem L. D. and Cath T. - A scaling mitigation approach during direct contact membrane distillation, Separation and Purification Technology 80 (2011) 315-322.

69. Tu K. L., Chivas A.R., and Nghiem L.D. - Effects of membrane fouling and scaling on boron rejection by nanofiltration and reverse osmosis membranes, Desalination 279 (2011) 269-277.

70. Tijing L. D., Woo Y. C., Choi J. S., Lee S., Kim S. H., and Shon H. K. - Fouling and its control in membrane distillation - A review, Journal of Membrane Science 475 (2015) 215-244.

71. Warsinger D. M., Swaminathan J., Guillen-Burrieza E., Arafat H. A., and Lienhard V. J. H. - Scaling and fouling in membrane distillation for desalination applications: A review, Desalination 356 (2014) 294-313.

72. Park C., Kim H., Hong S., Lee S., and Choi S. I. - Evaluation of organic matter fouling potential by membrane fouling index, Water Science \& Technology 7 (2007) 27-33.

73. Nghiem L. D., Oschmann N., and Schäfer A. I. - Fouling in greywater recycling by direct ultrafiltration, Desalination 187 (2006) 283-290.

74. Zuo G. and Wang R. - Novel membrane surface modification to enhance anti-oil fouling property for membrane distillation application, Journal of Membrane Science 447 (2013) 26-35.

75. Duong H. C., Duke M., Gray S., Cath T. Y., and Nghiem L. D. - Scaling control during membrane distillation of coal seam gas reverse osmosis brine, Journal of Membrane Science 493 (2015) 673-682.

76. He F., Gilron J., Lee H., Song L., and Sirkar K. K. - Potential for scaling by sparingly soluble salts in crossflow DCMD, Journal of Membrane Science 311 (2008) 68-80.

77. He F., Sirkar K. K., and Gilron J. - Studies on scaling of membranes in desalination by direct contact membrane distillation: $\mathrm{CaCO}_{3}$ and mixed $\mathrm{CaCO}_{3} / \mathrm{CaSO}_{4}$ systems, Chemical Engineering Science 64 (2009) 1844-1859. 
78. Gryta M. - Alkaline scaling in the membrane distillation process, Desalination 228 (2008) $128-134$.

79. Meng S., Ye Y., Mansouri J., and Chen V. - Crystallization behavior of salts during membrane distillation with hydrophobic and superhydrophobic capillary membranes, Journal of Membrane Science 473 (2015) 165-176.

80. Gilron J., Ladizansky Y., and Korin E. - Silica fouling in direct contact membrane distillation, Industrial and Engineering Chemistry Research 52 (2013) 10521-10529.

81. Al-Karaghouli A. and Kazmerski L. L. - Energy consumption and water production cost of conventional and renewable-energy-powered desalination processes, Renewable and Sustainable Energy Reviews 24 (2013) 343-356.

82. Khayet M. - Solar desalination by membrane distillation: Dispersion in energy consumption analysis and water production costs (a review), Desalination 308 (2013) 89101.

83. Carlsson L. - The new generation in seawater desalination SU membrane distillation system, Desalination 45 (1983) 221-222.

84. Banat F., Jwaied N., Rommel M., Koschikowski J., and Wieghaus M. - Performance evaluation of the "large SMADES" autonomous desalination solar-driven membrane distillation plant in Aqaba, Jordan, Desalination 217 (2007) 17-28.

85. Criscuoli A., Carnevale M. C., and Drioli E. - Evaluation of energy requirements in membrane distillation, Chem. Eng. Process. 47 (2008) 1098-1105.

86. Lin S., Yip N. Y., and Elimelech M. - Direct contact membrane distillation with heat recovery: Thermodynamic insights from module scale modeling, Journal of Membrane Science 453 (2014) 498-515.

87. Saffarini R. B., Summers E. K., Arafat H. A., and Lienhard V. J. H. - Technical evaluation of stand-alone solar powered membrane distillation systems, Desalination 286 (2012) $332-341$.

EiC queries:

Check if ref [72] is correct?. 